Review

\title{
Greening the Ivory Tower: A Review of Educational Research on Sustainability in Post-Secondary Education
}

\section{Philip Vaughter $^{1, *}$, Tarah Wright ${ }^{2}$, Marcia McKenzie ${ }^{1}$ and Lauri Lidstone $^{3}$}

1 College of Education, University of Saskatchewan, 28 Campus Drive, Saskatoon, SK S7N 0X1, Canada; E-Mail: marcia.mckenzie@usask.ca

2 School of Environmental Science, Dalhousie University, 1355 Oxford Street, P.O. Box 15000, Halifax, NS B3H 3Z1, Canada; E-Mail: tarah.wright@dal.ca

3 School for Resource and Environmental Studies, Dalhousie University, 6100 University Avenue, Suite 5010, P.O. Box 15000, Halifax, NS B3H 3Z1, Canada; E-Mail: lauri.lidstone@dal.ca

* Author to whom correspondence should be addressed: E-Mail: philip.vaughter@usask.ca; Tel.: +1-306-966-5263; Fax: +1-306-966-2319.

Received: 30 March 2013; in revised form: 6 May 2013 / Accepted: 15 May 2013 /

Published: 21 May 2013

\begin{abstract}
There is a deficit of multi-site studies examining the integration of sustainability in the policies and practices of post-secondary institutions. This paper reviews what comparative empirical research has been undertaken on sustainability in post-secondary education (PSE) within eight leading international journals publishing on sustainability and education. Three predominant themes of research on the topic are identified within the review: research comparing sustainability curricula across institutions (both within specific disciplines of study and across disciplines); research comparing campus operations policies and practice across multiple institutions; and research on how to best measure or audit approaches and outputs in sustainability in PSE. This review of the research literature supports the contention within the literature on sustainability in PSE that most research on the topic is focused on case studies rather than comparison of multiple institutions. The comparative research that is emerging from the field is concentrated on assessing measurable outputs for environmental externalities within institutional operations, with little examination of sustainability uptake and outcomes across broader institutional policies and practices.
\end{abstract}


Keywords: sustainability; post-secondary education; higher education; curriculum; sustainability policy; sustainability measures

\section{Introduction}

A focus on sustainability in post-secondary education (PSE) institutions can be traced to origins in the 1978 United Nations International Environmental Education Programme [1]. As the field began to develop further during the $1980 \mathrm{~s}$, there were calls for sustainability policies and practices to be integrated into post-secondary education institutions. These recommendations were then codified in a number of international declarations and charters during the 1990s and the first decade of the $21 \mathrm{st}$ century, including in the Talloires Declaration (1990), the CRE Copernicus Charter (1994), the Ubuntu Declaration (2002) and the Rio +20 Declaration (2012). These international developments have been paralleled in regional and national declarations of university and college alliances [2], community college associations [3] and international alliances [4]. At the same time and, in some cases, in response to becoming signatories on such declarations, many post-secondary institutions around the world have engaged in sustainability-related initiatives.

The term sustainability is multi-faceted and varies in its definition, and as a result, it can be difficult to implement sustainability in PSE in practice or to research it as a concept. For the purposes of this review, the term sustainability is discussed in relation to PSE using the following five categories: (i) the integration of sustainability into curricula, (ii) the integration of sustainability into all facets of the management of institutions (i.e., governance), (iii) engagement in research focused on sustainability topics, (iv) institutional involvement in community engagement on sustainability issues and (v) integration of sustainability into facility operations [5]. The Global University Network for Innovation (GUNI) (2012) recently reviewed how sustainability is occurring in PSE globally in four of these five categories: research, curricula, community engagement and facilities operations. Their report details that uptake of sustainability within PSE institutions is increasing across the world, though at varying rates among the different categories. In many cases, this has occurred in collaboration with emerging regional networks for sustainability [6].

While empirical research examining sustainability in PSE has increased in the scholarly literature substantially since the early 1990s [1], the majority of this research has been conducted as case studies within individual institutions. Corcoran et al. [7] contend that case study research on sustainability in PSE has not lived up to its potential for improving sustainability in post-secondary education, because of the lack of comparative studies (in this context, "comparative research" refers to studies comparing and contrasting multiple PSE institutions' policies and practices in regards to sustainability initiatives). Likewise, others have indicated that there is a lack of research examining the implementation of sustainability in post-secondary education institutions from a comparative angle [8,9]. Without comparative research, there is little understanding of the degree to which conceptualizations and practices of sustainability in PSE are convergent or divergent [10]. There are some meta-analyses type reviews of individual site studies: for example, Karatzoglou [11] provides an excellent comparative analysis of research methodologies used to examine sustainability in PSE institutions, while 
Mochizuki and Fadeeva [12] compare how sustainability is contextualized and competencies in sustainability are assessed in various studies. However, these types of reviews are in the minority. Indeed, studies that themselves gather data on sustainability uptake in PSE research across multiple institutions, which compare and contrast how sustainability policy is developed, how sustainability practices are implemented and where both may be coming up short, are still relatively lacking.

With an aim of laying some of the groundwork for an expanding body of comparative research, this paper reviews the comparative empirical research that currently exists within the education literature. It, thus, critically examines and contrasts the trends and gaps evident within the existing cross-institutional research on sustainability in PSE institutions' policy and practice. However, as Karatzoglou [11] notes, the research literature on education and sustainability, "is abundant, vaguely defined and so fast emerging that (it) would make efforts for full coverage impractical and infeasible" (p. 3). Sifting through all the existing literature on sustainability and education to find all empirical comparative research on sustainability in post-secondary education institutions is, thus, a challenging task. Rather than an exhaustive review, the intent here is to disentangle some of the existing threads of comparative research examining sustainability in PSE institutions, so as to provide a review of the topic and possible directions for further research.

\section{Review Methods}

The broad and interdisciplinary Academic Search Complete (ASC) database was used to search for relevant existing research in order to review as broad a body of relevant literature as possible. This database was used in conjunction with the Education Resources Information Center (ERIC) database to provide a more detailed search of literature focused on education. A Boolean search was undertaken in these databases using the terms "higher education" OR "postsecondary education" OR "post-graduate education" AND "sustainable" OR "sustainable development" OR "sustainability" AND "policy" OR "practice" in the titles, keywords or abstract of the database(s) documents. The term "environment" was intentionally omitted to mirror the methodology of a previous bibliometric study, which distinguishes between the terms environmental education and sustainability education [1]. Wright and Pullen [1] omit the term "environment" in their search to indicate that "sustainability" is a broader term than "environment", in that it also encompasses social and economic considerations, as they relate to environmental issues. Many of the initial search "hits" were omitted, due to being conceptual, rather than empirical, studies. Of those empirical studies that have been undertaken, many pre-date the official declaration of the Decade of Education for Sustainable Development (DESD) from 2005-2014 and have already been reviewed elsewhere in earlier publications [9]. For this review, we therefore chose to retrieve English language manuscripts that were published between the years 2003 and 2012, in order to provide an overview of the literature published since the DESD was announced by the United Nations (2003), as we are aware of no other published reviews of comparative empirical research conducted during this time period.

A total of 1,193 titles were collected during the first Boolean search. Of these titles, 896 (75\%) were journal articles published between 2003 and 2012 (Figure 1), with 272 (30\%) being published in one of the following eight journals, which are well-known in the area of sustainability and education: the International Journal of Sustainability in Higher Education $(n=153)$, Environmental Education 
Research $(n=26)$, the Journal of Education for Sustainable Development $(n=25)$, the Journal of Cleaner Production ( $n=17)$, Planning for Higher Education $(n=17)$, Higher Education Policy $(n=12)$, Facilities Manager $(n=12)$ and Community College Journal of Research and Practice $(n=10)$ (Figure 2). Drawing upon Fink's [13] technique for a "sensitivity analysis" in a literature review, it is appropriate to sample from journals publishing the most articles on the topic, with the hopes of capturing a high proportion of the top quality studies within a given field. While this review focused on manuscripts published in the aforementioned eight journals during the given time period, key articles identified from outside these eight journals (and indeed, from outside education journals) were included in the analysis to help address gaps in the research published from the eight leading education related journals.

Figure 1. Numbers of articles on "sustainability" in postsecondary education within education-related journals between 2003-2012.

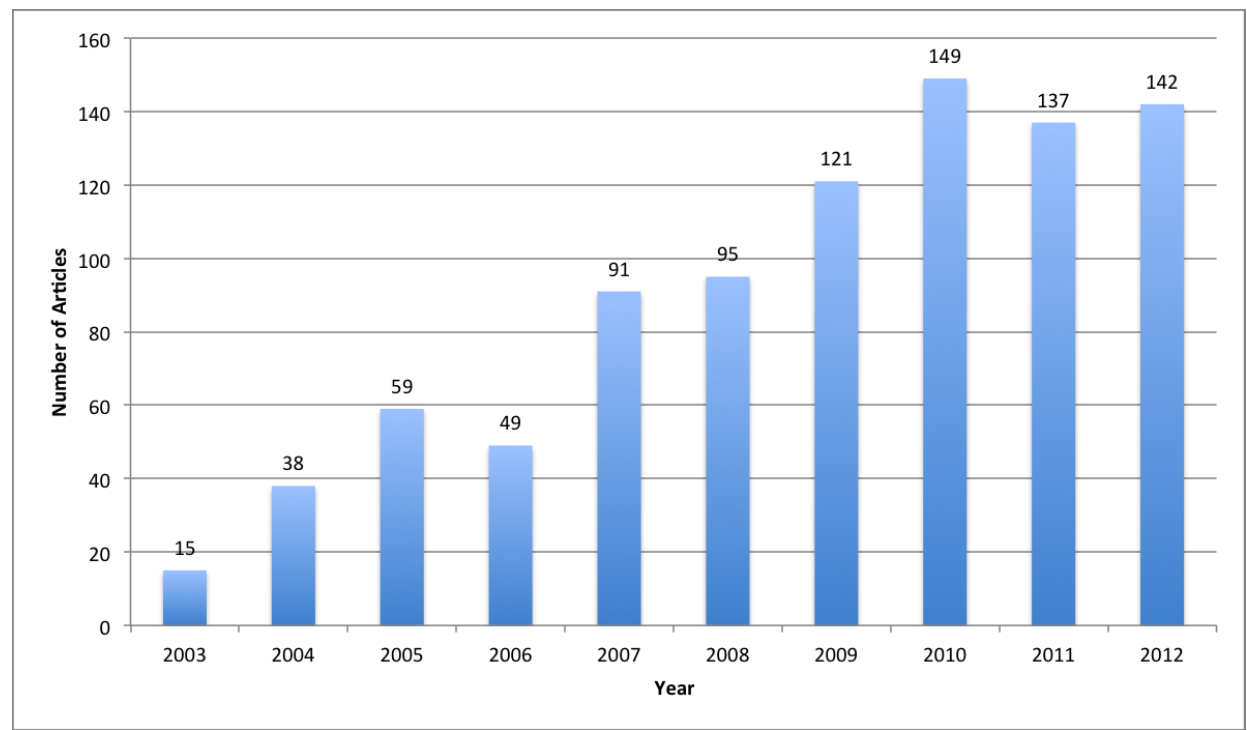

Figure 2. Top eight education-related journals publishing articles on "sustainability" in postsecondary education between 2003-2012.

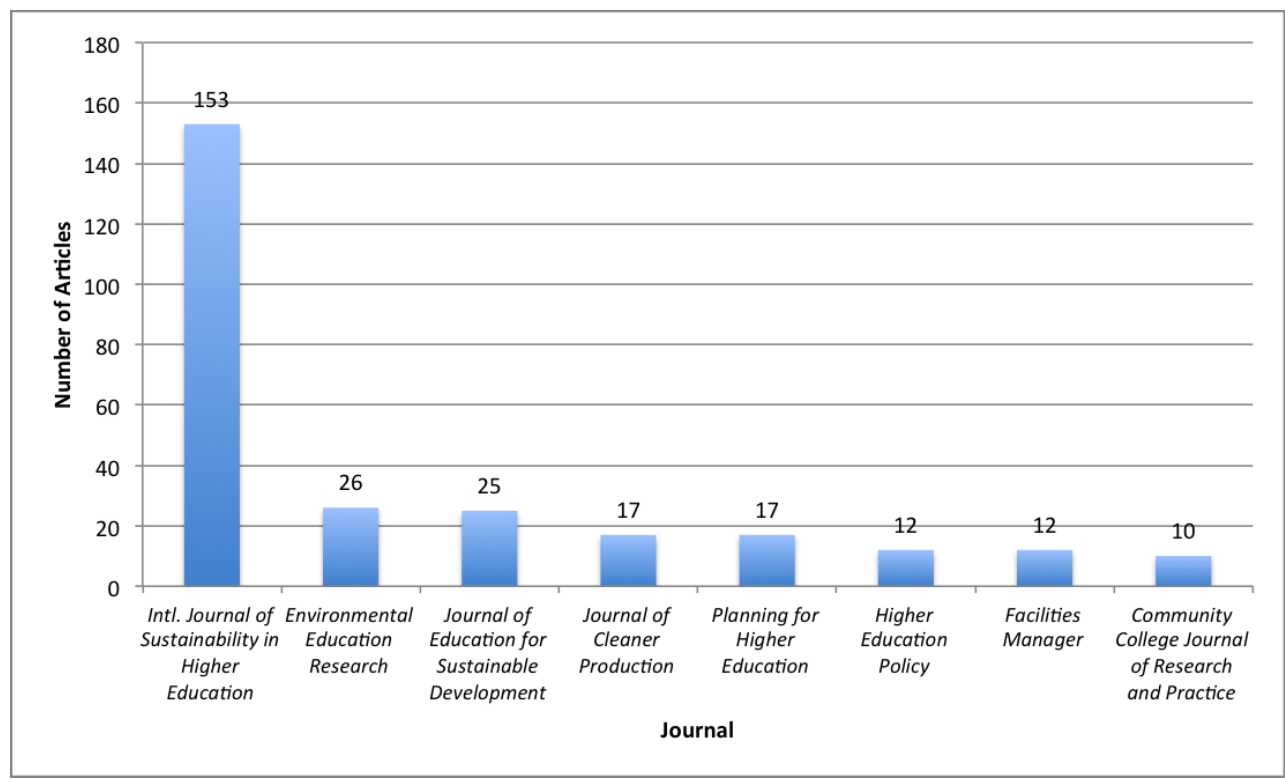


The abstracts of the resulting 272 journal articles from the eight leading education-related journals were reviewed to determine the nature of the particular studies (i.e., empirical vs. theoretical research) and scope (i.e., single site vs. multiple site or "comparative"). Next, since our primary concern was examining comparative empirical research, articles outside of our area of interest (e.g., theoretical pieces, works focusing on case studies of individual institutions or programs within individual institutions) were omitted. The articles were categorized as comparative if they focused on the study of two or more PSE institutions. They were considered empirical if the focus of the research were quantitative or qualitative collected data, rather than theoretical constructs. Thus, only articles that empirically examined aspects of sustainability in two or more PSE institutions were selected. This left a total of 103 journal articles that met the criteria within the eight journals. Upon examining these articles, 14 additional key works were added to the review in order to address gaps in the research within the education-related literature, making a total of 117 articles and reports that were included in the review.

A grounded content analysis of this research literature was subsequently conducted, drawing upon Mayring's [14] criterion for categorization in qualitative research. Mayring's criteria for systematic qualitative analysis include inductively forming initial categories from the manuscripts, inductively developing sub-categories within these and revising the categorizations through an iterative process known as a feedback loop. The formation of the categories for our review was informed by the main question under consideration: what types of comparative empirical studies have been undertaken that examine sustainability in PSE? To address this, the analysis of the articles reviewed therefore focused on the research questions posed in each of the manuscripts. The primary research questions posed within the articles were than hand coded. Types of research questions were then categorized using step-by-step inductive category development. From here, some of the research questions were also put into subcategories. Using Mayring's [14] prescribed feedback loop for subsuming and revising categories, the predominant themes within the literature were determined inductively after the reading and hand coding of the articles. It should be noted that while content analysis is a robust tool for extracting themes and frames from literature, the frames and themes extracted are those the coder(s) identifies and prioritizes. There are no universal truths within the process, and thus, different coders will likely emphasize different narrative strands. While consensus was reached on the predominant themes in this review, it should be remembered that this is a process of categorization and not definitive description.

\section{Results and Discussion}

Our content analysis of existing comparative empirical studies on sustainability in PSE revealed considerable variation across the existing studies in terms of comparative research methodologies, locations in which studies were undertaken of PSE institutions engaging with sustainability policy and practice (e.g., Africa, the Americas, Asia, Europe, Oceania) and scales at which different institutions are being compared to one another (local, national, regional, global). Further, our analysis of the literature revealed three predominant themes of existing comparative research on sustainability in PSE:

- Research comparing sustainability curricula across institutions (both within specific disciplines of study and across disciplines);

- Research comparing campus operations policies and practice across multiple institutions; and 
- Research on how to best measure or audit approaches and outputs in sustainability in PSE.

The following review of the research is organized according to these three categories and begins with an overview of existing research comparing sustainability curricula across institutions.

\subsection{Curricula}

Of the 103 articles examined, approximately one-third $(n=37)$ provided comparative analysis of how sustainability was integrated into curricula across multiple PSE institutions. Rusinko [15] supplies a useful heuristic for reviewing how sustainability concepts are integrated into PSE curriculum (see Table 1).

Table 1. Rusinko's (2010) matrix for integration of sustainability concepts into curricula.

\begin{tabular}{ccc}
\hline & Existing Structures & New Structures \\
\hline & I. Integrate into existing & II. Create new, discipline-specific \\
Narrow (discipline-specific) & course(s), minor(s), major(s) & sustainability course(s), minor(s), \\
& or program(s) & major(s) or program(s) \\
Broad (cross-disciplinary) & III. Integrate into common & IV. Create new, cross-disciplinary \\
& core requirements & sustainability course(s), minor(s), \\
& major(s) or program(s)
\end{tabular}

This $2 \times 2$ matrix considers the integration of sustainability concepts in both existing and new curricula at both broad (interdisciplinary) and narrow (discipline-specific) scales. Interestingly, the majority of articles written on integrating sustainability into curricula (i.e., 26 of the 37 articles) focus on detailing the integration of sustainability into discipline-specific and existing course work within PSE (i.e., quadrant I of Rusinko's matrix). Most of this research examines the integration of sustainability in curricula in technical fields, such as engineering and science. For example, in a review of sustainability in engineering curricula at multiple institutions internationally, Mulder et al. [16] found that the topical focus on sustainability has shifted over the past decade to focus more on sustainability in terms of product life-cycle analysis and long-term planning in engineering projects. This same trend is noted an assessment of engineering and computer science curricula in China's PSE institutions [17]. The existing research also suggests that not all attempts to integrate sustainability into discipline-specific science and engineering curricula are success stories. In their overview of Canadian universities, researchers found that an increasing number of institutions were offering course work integrating sustainability concepts into environmental assessment (EA) training, but that most of the courses were cursory in nature, providing little room for thinking critically about environmental problems [18]. Additionally, research emanating from the UK indicates that while there is a high interest for incorporating sustainability concepts into bioscience laboratory courses, uptake is usually hindered by lack of institutional support and time constraints [19].

Thus the review of the relevant literature reveals that the emphasis on existing research on sustainability in curricula tends to be within the technical fields, echoing Sherren's [20] findings in her study of Australian universities. Sherren also found that when sustainability was integrated into curricula in the institutions she studied, it was framed as technological innovation as opposed to cultural or behavioral change. The current review of the existing research also suggests that, more 
broadly, the majority of curricula that are studied in relation to sustainability emphasizes innovation (be it technical with engineering courses or market-based for business courses) over change of a behavioral or cultural nature.

While the curricula of technical fields constitute the focus of the majority of research on sustainability uptake in PSE curricula, other fields are also being examined. McKeown [21], for example, researched the level of integration of sustainability into education curricula over the last two decades, noting the growing number of PSE institutions offering training in sustainability education across the globe. Recently, there has also been an increase of research on how sustainability is integrated into business curricula of different institutions [22,23]. One reason for the lack of research on sustainability uptake in broader disciplines may be the lack of professional development training in PSE institutions designed to facilitate faculty integrating sustainability concepts into their curricula. In a 2008 examination of 38 Australian universities, only a single institution offered its faculty training opportunities on incorporating sustainability into their curricula [24].

In studies examining uptake of sustainability across disciplines, Geli de Ciurana and Filho's [25] study of 11 European and Latin American universities found 10 common characteristics for successfully "greening" existing curricula across all post-secondary disciplines. These included permeability of disciplines within institutions (and, thus, the ability to work interdisciplinarily), establishing a relationship between theory and practice in course work and creating space for reflection on curricula. In research on the South Pacific Island Nations, it has been found that sustainability tended to be integrated into all curricula in PSE [26]. A cross-institutional study from 2008 also found that integration of sustainability principles is on the increase across a wide range of extra-curricular activities in a number of PSE institutions within the UK [27]. With these exceptions, studies comparing approaches to sustainability in the curriculum across different disciplines were found to be rare in our analysis.

Our review also revealed that critical analyses of how PSE curricula integration efforts compare in their outputs across institutions is largely absent in the literature (e.g., possible outputs being increased knowledge of sustainability issues, behavioral or action-oriented change or other learning outcomes). This is consistent with Davis et al.'s [28] findings that the comparative research that does exist on sustainability outcomes in PSE focuses on university operations and governance, with little attention paid to curricular or teaching/learning outcomes. None of the comparative empirical studies reviewed touched on assessment of learning outcomes for sustainability in curricula. One reason for this may be the difficulty associated with objectively measuring learning outcomes. Savelyeva and McKenna [29] discuss this difficulty when they suggest using the Global Seminar (GS) model to measure sustainability thinking, as opposed to sustainability learning, when measuring the outcomes on the incorporation of sustainability curricula. However, research on how students are "thinking" about sustainability in relation to, or as a result of, PSE sustainability curricula are also absent from the comparative literature.

The concept of measuring sustainability "thinking" as opposed to sustainability learning is reviewed extensively by Wiek et al. [30]. In their work on key competencies in education for sustainability, they also note that learning outcomes for competencies in sustainability education are not adequately operationalized. Despite the dominance of "laundry lists" for sustainability competencies appearing in different PSE institutions discussed in the literature, they amalgamate five key competencies for 
sustainability learning: systems-thinking competence, anticipatory competence, normative competence, strategic competence and interpersonal competence. Rieckmann [31] also stresses the importance of system-thinking and anticipatory competence in an overview of key competencies viewed as critical by sustainability educators from Europe and Latin America, listing ten additional key competencies. It is interesting to note that neither of these empirical, comparative research papers on key competencies for sustainability within PSE [30,31], are situated within the education literature. Instead, both reviews appear in journals focusing on sustainability as a field in general, not on education in particular.

In summary, key areas of existing comparative research on sustainability in PSE that focus on curriculum include the uptake of sustainability in technical and science oriented curriculum, the uptake of sustainability in education curriculum and a lack of integration of sustainability across disciplines $v s$. greater discipline-specific integration. Some debate exists as to whether existing curricula should be "greened" or whether new curricula on sustainability should be introduced; however, the majority of the literature reviewed stressed that sustainability needs to be included if topics in postsecondary education are to remain relevant to students' lives. The application of critical thinking skills to issues of sustainability is also stressed throughout the literature.

\subsection{Comparing Campus Operations Policies}

The second significant area of existing research identified in our review of the literature were those studies comparing campus operations policies and practices at multiple institutions. Almost half of the total number of articles analyzed in the review $(n=51)$ focused on PSE institutions' operations policies, including in relation to electricity use, waste disposal, greenhouse gas (GHG) production and emissions, as well as any other policies addressing environmental externalities from the physical operation of PSE institutions. These articles can be divided into those that focused on campus operations policies that were formed in response to national policies around sustainability, those that focused on operations policies that developed within networks of PSE institutions in the North American context and those that focused on how sustainability operations policies and practices from the corporate world can be applied to PSE institutions, as will be outlined in this section.

In an international comparison of universities in India, Japan, Spain, Sweden and the United States, a group of researchers illustrate that the initial uptake of sustainability into operations policies is often the most difficult hurdle that PSE institutions must overcome in order to manage their facilities in a more sustainable fashion [32]. Their research suggests that the main drivers for initial uptake of sustainability into campus operations policies are (i) a high level of coordination on sustainability projects within institutions, (ii) the presence of people who act as "connectors" or those who are able to bridge gaps across disciplines and between operational and academic departments and (iii) available funding for innovation in operations. In the broader reviewed research articles, the necessity of strong communication and leadership to initiate, maintain and drive sustainable operational policy was stressed repeatedly. For example, a study by James and Card [33] points to the necessity for strong leadership as a precursor to the uptake of operational initiatives on sustainability in their comparison of three university campuses in the United States. Other research suggests that faculty and staff leaders tend to have a more significant role in the long-term implementation of operational initiatives around sustainability within institutions, though collaboration with administrators is still crucial for clearing 
initial hurdles in adopting operational policy [34]. In addition to the importance of leadership, the existing comparative research suggests that communication between the institution and the surrounding community on regional sustainability challenges is also an important factor for successful uptake of sustainable operational policies across cultures and nations [35].

Furthermore, while sustainability initiatives in PSE facility operations appear to be flourishing, research by Velazquez et al. [36] suggests that the conditions necessary for successful implementation of initiatives are absent from many universities internationally. They point to a lack of communication, support and training as reasons for this, as well as a culture that fosters resistance to change throughout academia. For instance, Pearce's [37] research found that universities could use their considerable purchasing power to invest in alternative energy and spur the solar energy market in the United States, but none have moved to do so. Dale et al. [38] also note that universities can be reluctant to embrace sustainability tactics. In their investigation, they found using online communication at PSE institutions, similar to how it is used in teleconferencing in business, facilitates knowledge generation effectively, with the added benefit of saving time and money and having less of an environmental impact. However, they found that most post-secondary education institutions still have not changed policies, mandating students' physical attendance on campus.

Our review also highlights the role of the governments in helping to facilitate sustainable operations policies in PSE institutions, especially within the Asia-Pacific region. For example, an examination of PSE operational policies throughout this region reveals the strong role government policies have in spurring the development of institutional policies in nations, such as Australia, China, Japan and the Philippines [39]. However, while many individual institutions in these countries are implementing new sustainable operations policy initiatives, a recent overview of the region has found that despite a high level of government support for sustainability initiatives in PSE operations, there is an insufficient level of collaboration among PSE institutions in the region compared to PSE sustainability networks in other regions [23]. The experience of Japanese PSE institutions is one of sustainable operations policy being directed by the government, in this case, via the Ministry of Education and the Ministry of Environment. Because the push to incorporate sustainability into PSE operations' policies has come from the Japanese government, university administrations in Japan have grown dependent on the ministries for innovation and leadership, rather than using their own considerable resources to pursue sustainability targets [40]. However, in the Philippines, while national government agencies promote curriculum development in relation to sustainability in PSE, the NGO Environmental Education Network of the Philippines (EENP) has taken a leading role in the operational approach to sustainability policy in PSE with its Dark Green Schools (DGS) program [41]. In India's national education policy, the country's highest court mandates environmental education at all levels of formal education, including PSE. However, the implementation of sustainable operational policies within India's universities has been stymied by a lack of communication among stakeholders, as well as conventional assessments for sustainable operations competing with traditional PSE assessment measures [42].

The reviewed research suggests that national governments have also provided much of the motivation for adopting sustainable operational targets within Europe. In Sweden, all universities have submitted environmental impact reports since 1996. This is in line with a directive from the Swedish government in the same year that all public authorities contribute to sustainable development for 
society. Universities in Sweden that adopted environmental management systems (EMSs) earlier, performed better than those who adopted EMSs later, suggesting there is learning curve for implementing sustainable operations policy strategies within individual institutions, despite similar directives nation-wide [43]. Swedish universities also seem particularly concerned about direct environmental aspects (for instance paper use and electronic waste handling), emphasizing operational sustainability, as opposed to education and community outreach, on sustainability issues [44]. Similar findings from the UK indicate that sustainable operations policies are emphasized across universities in response to government policy, with little opportunity for reflection or adaptation on other facets of sustainability within PSE [45].

The research suggests that sustainability-related operations policies within North American PSE institutions are much more diverse than in Asia or Europe, due to the lack of national government initiatives around sustainability initiatives. In the absence of national incentives, a number of sub-national (regional or state/provincial) and non-governmental programs have surfaced to incentivize sustainability operations among PSE institutions in the USA and Canada. North American institutions participating in the Sustainability Tracking and Rating System (STARS) provided by the Association for the Advancement of Sustainability in Higher Education (AASHE) are recognized as being on the cutting edge of operations innovation globally [46]. However, our review illustrates that while a number of innovative sustainable approaches to university operations are detailed in the reviewed literature on North American universities and colleges, the operations policies appear much more piecemeal and inconsistent than in either East Asia or Europe. For example, Beringer et al. [47] summarize that sustainability in physical operations for institutions in Atlantic Canada remains largely unaddressed. In a study of American institutions, it was found that historically California's PSE institutions have led the charge for sustainable building operations in US post-secondary education [48]. Institutional operations developments in the US range from sustainability landscaping strategies $[49,50]$ to policies for sustainable building design on campus [51,52]. This is in contrast to PSE operations to increase institutional sustainability being derived from national policy directives, as in Sweden [44] or Japan [40], where one seems more uniform and consistent uptake of sustainability in PSE operations across the given country.

Our review also suggests that the links between PSE operations policies and the supply chains on which they are dependent are often overlooked in the research literature, especially in North American institutions. For example, Williamson [53] demonstrates that institutions' housing and enrollment policies are responsible for the production of more greenhouse gas (GHG) emissions and increases in energy usage, than the savings obtained through the reduction based on the energy or operations sustainability policies of those same universities. For instance, housing policies have tended to push students further and further from campuses, as student populations have soared, necessitating the need for GHG producing transit for more commuters. Many institutions have sustainable operational innovations for decreasing their GHG production and increasing energy efficiency, such as mass transportation initiatives or mandates around energy efficiency in campus buildings. However, Williamson demonstrates that the GHG offsets from practices, such as instituting carpooling policies, are negligible when compared to rising student populations and longer student commutes in a number of institutions. Also, research by Comm and Mathaisel [54] establishes that while campus policies in American universities may emphasize sustainability, institutional supply chain management is almost 
universally unsustainable and GHG intensive across PSE institutions in the USA, especially when compared to the business sector. The same situation appears in the Nigerian context, with sustainability efforts at individual institutions unable to keep pace with the tremendous impact of growth in the post-secondary education sector [55]. While some studies were found comparing the sustainability operational policies of PSE institutions with those of businesses, no articles detailed an actual institution-wide uptake of corporate sustainability operations policies within a PSE institution. It is unclear whether this is because the practice of doing so is untried or because research into any attempts to do so has not been forthcoming to date. An exception to this is within the supply chains for college and university dining services, where growing pressure from students across the United States has impacted institutions' decisions to adopt sustainable sourcing practices from the food industry. Many university dining services are beginning to draw on the supply chain principles of restaurants and grocery stores that look to source their food stocks sustainably. This has been in large part due to student pressure on universities' administrations [56,57].

Observing that many universities are much like small cities in and of themselves, Finlay and Massey [58] apply Register's [59] concept of an eco-city to their study of a number of American PSE institutions. Register's [59] concept of an "eco-city" is defined by a set of criteria, including the degree to which an institution addresses a self-contained economy, carbon neutral operations, well-planned city layout and public transportation, resource conservation, the restoring of environmentally damaged urban areas, housing and economic equity, as well as a number of other criteria. While the study found that none of the American campuses studied embraced all of Register's criteria for sustainability, they noted that many institutions were strong contenders for fully embracing the "eco-city" framework [58]. They note that while many universities tend to possess a number of alternative transportation options and participate in recycling and conservation programs, they also tend to be carbon and energy intensive. Research by Su and Chang [60] also examine ways for making PSE institutional operations more sustainable, though their research focuses on PSE institutions as part of a larger community. They examine how sustainability concepts were disseminated between PSE institutions and surrounding communities in Taiwan, through a series of projects to connect sustainable practices in PSE to their surrounding communities.

In summary, almost half of the literature reviewed on sustainability in PSE consisted of research centering on operations policies. This literature was split between those studies examining sustainable operations policy, which flows out of policy directives from national governments or national NGO networks and those that focused on sustainability operations, which emerged either within a PSE institution or among a network of PSE institutions, especially within North America. A final portion of the studies centered on examining sustainability operations policy from the corporate world and how they could be applied to PSE institutions.

\subsection{Measuring Sustainability}

The third and final distinct theme that emerged from a content analysis of the comparative literature on sustainability in PSE is research focused on measuring or auditing approaches and outputs of sustainability initiatives across institutions. Of the total 103 articles coded and analyzed, less than 15\% $(n=15)$ fit into this category. While assessment instruments do exist to evaluate the role of 
sustainability in non-operational realms (e.g., education, governance, research and community engagement) for PSE institutions, discussion of these assessment instruments is by and large confined to academic periodicals not focused on education research (e.g., Futures, Sustainability, Sustainability Science). Somewhat ironically, most of the existing research on sustainability assessment instruments in PSE institutions within education-related journals discussed audits of operational outputs and not assessments of curricular outcomes. In this section, we review the existing literature on assessment tools used to measure sustainability within PSE institutions, which focuses on the two sub areas: (i) auditing tools that can be used to measure sustainability initiatives and (ii) outputs that can be measured when assessing sustainability.

While a number of assessment instruments for evaluating PSE institutions' sustainability outputs are mentioned in the literature, some are more common than others. In reviewing the frameworks for sustainability assessment used by various PSE institutions, the AASHE's STARS rating system and the Campus Sustainability Assessment Framework (CSAF) are the predominant tools used in North America for assessing campus sustainability [61]. They are both based on self-reports provided by institutions of their sustainability policies and practices in relation to different domains, such as governance, research, facilities' operations, community engagement and curricula. While the CSAF has proved popular with a number of non-governmental organizations for assessing campus sustainability, several studies have noted that many PSE institutions shy away from using it, because of the demands it puts on volunteers in assessing all 175 indicators [62,63]. While institutions using these types of frameworks also report on non-operational outputs (e.g., in areas of curriculum, research, etc.), the majority of the reviewed research literature on self-reporting sustainability frameworks of assessment, such as STARS or CSAF (11/15 articles), focused on operations outputs. Interestingly, despite the AASHE STARS framework's mentioned in eight of the 15 articles on the topic of sustainability assessments, none of the reviewed research compared operations policy or outputs between different PSE institutions with STARS ratings.

Outside of North America, the assessment instrument for sustainability in higher education (AISHE) developed in the Netherlands, and the alternative university appraisal (AUA) developed in Japan are other national assessment models. The AISHE system has been used to assess sustainability education in a number of PSE institutions across Europe, while the AUA has been used to examine the uptake of sustainability in education, governance, research and community engagement within PSE institutions located in the Asia-Pacific region. In using AISHE, Roorda and Martens [64] notice that sustainability in education is best assessed within separate programs or departments of a given university, due to the methodological and developmental differences that exist between faculties within a university. They go on to note that this can make cross-curricular comparison of sustainability difficult, even within the same institution. They also note that AISHE tends to be used in departments of engineering, science and education, paralleling this review's findings on sustainability in curricula. One exception to the trend of auditing only for operational performance in relation to sustainability is the Sustainability in Higher Education Institutions (SusHEI) model, which does take university dimensions, such as education and research into account and which has been piloted at a limited number of institutions in Portugal [65]. Recently, Di Giulio et al. [66] proposed a set of indicators for education for sustainability in German speaking PSE institutions in Europe; however, the implementation of assessing these proposed indicators is still in development in the Austrian, German 
and Swiss postsecondary education systems. And in looking at indicators across an international range of institutions, a 2009 study has proposed adapting the Global Monitoring and Evaluation Framework (GMEF) from the UN to examine indicators for sustainability in education, such as uniform structures, processes and outcomes across educational entities [67]. However, she also points out that a lack of baseline data could make adapting this system for assessing sustainability education problematic. This is especially true for PSE institutions, where practices and policies tend to be diverse within national contexts, let alone international ones.

The research literature reviewed for this study supports the findings of other researchers in the education field, who found that the majority of academic literature on sustainability assessment tools focus on environmental impact of university operations, with less attention focuses on education (curricula), research, governance or community engagement [68]. This gap observed in our literature review also supports recent research, which found a lack of auditing of non-operations activities among PSE institutions in the running for the Austrian Sustainability Award [69]. Possible departures from this theme include research papers engaging with the SusHEI and the AISHE framework evaluations of non-operational aspects of PSE sustainability, though reviews of these frameworks did not appear in journals focused in education. Measurements of operational outputs in relation to sustainability, also called "eco-audits", are also still quite popular among PSE institutions [70].

Research on sustainability auditing and reporting within post-secondary education is still limited in number and scope compared to sustainability reporting in the business community [71]. The transfer of sustainability assessments from the business world into the realm of post-secondary education is explored in Walton and Galea's [72] theoretical examination of American universities. The researchers note businesses were better at tying efficiency policies to local sustainability initiatives in the communities they are embedded in, while critiquing some universities for viewing their non-profit status as a license to be inefficient with resources. Roorda and Martens [64] report that quality management tools developed by the business world and utilized by PSE institutions to assess environmental sustainability in Europe include tools developed by the International Organization for Standardization (ISO) and the European Foundation for Quality Management (EFQM). In comparing university auditing of sustainability practice for universities in New Zealand, Fisher [73] suggests that the ISO 14000 series of environmental standards would be useful for campuses commencing sustainability reviews. The same recommendation exists for universities in the UK [74]. In 2007, a scheme titled "Universities that Count" was promoted by the British Environmental Association for Universities and Colleges (EAUC) in collaboration with the business organization Business in the Community, in order to bring sustainability policies from the business world into the realm of PSE institutions [75]. The scheme was based on business models for sustainable operations policy, but was discontinued in 2010 in part because of the non-holistic approach to sustainability in the model. A new scheme was launched in the UK by the EAUC during 2012: Learning In Future Environments (LIFE) was designed to take into account social responsibility, as well as environmental sustainability in performance improvement for PSE institutions. Student networks are also playing an important part in sustainability assessments in the UK, with groups, such as People and Planet, providing guides for measuring PSE institutions performance in a number of areas relating to sustainability [76].

A reoccurring question in all of the research on assessing sustainability in PSE institutions is that of what outputs should be measured? While metrics for assessing PSE targets for sustainability tend to 
need quantifiable parameters for comparative purposes, an examination of American universities assessed the importance of keeping assessment framework designs flexible in terms of time scale and other situational factors to allow for institutional differences, such as size, location and other demographic variables [77]. On the other hand, too little coordination of measurement criteria among institutions can result in assessments with limited informative value, as was found in one study examining the diverse sustainability auditing processes observed in Canadian universities [78]. While operational outputs are emphasized among the universities researched in their study, the array of measures and the variety in what was measured made any comparison difficult. Indeed, the need for baselines on which to assess sustainability initiatives comparatively within PSE was a theme running throughout each of the articles addressing measurement. This theme is best summarized by a 2004 study, which emphasizes that while systematic assessment of sustainability in education is difficult and must be contextualized, it is also important for assuring quality of operational outputs, as well as the teaching and learning experience [79].

Our review illustrates that while research on the measuring of sustainability outputs is occurring, little consensus exists as to what should be measured, nor how precisely to measure it. Finally, our review revealed no literature on utilizing sustainability measures from other spheres of society to measure sustainability outputs in PSE institutions, such as government auditing programs. Only the business sector is examined in terms of best practice for sustainability and, here, only in terms of operational outputs. It should be acknowledged that a platform of sustainability audits was recently launched at the United Nations Environment Programme (UNEP), with the set including STARS, LIFE and other assessment tools previously mentioned. Whether or not this platform will contribute to more integrated and/or uniform approach to how sustainability is assessed in PSE institutions remains to be seen.

\section{Conclusions}

While comparative investigations into institutional sustainability in PSE are not as abundant as case studies of individual institutions, a number of comparative studies have been carried out on the sub-national, national and international levels since the declaration of the DESD in 2003. This review has illustrated three of the dominant themes emerging from this published literature: research comparing sustainability curricula across institutions (both within specific disciplines of study and across disciplines); research comparing campus operations policies and practice across multiple institutions; and research on how to best measure or audit approaches and outputs in sustainability in PSE. While it is our intent to disentangle the many narrative threads of research into sustainability in PSE institutions, it must be acknowledged that some of these categories overlap to some degree, particularly operational initiatives for sustainability and the analysis of sustainability audits.

This overview has also illuminated gaps in the research within each of these emergent themes in the literature. For comparative studies investigating sustainability in PSE curricula, there has been an emphasis on integration of sustainability into science and engineering, with little attention paid to curricula in the humanities and social sciences. Within comparative literature on sustainability in campus operations, a number of studies examine where the impetus for operations policies comes from, but little work has been done in comparing how effective these policies are in affecting outputs and how that may vary among different PSE institutions. There is also a gap in the research literature 
critically comparing how PSE institutions' sustainability operations policies link to the larger community. Finally, in terms of existing comparative research on sustainability audits, the majority of studies examine operational outputs of institutions and do not focus on the evaluation of other dimensions of institutional sustainability, such as education, research, governance or community engagement. While multi-dimensional assessment tools, such as AASHE's STARS and the CSAF, exist, these type of tools are self-reporting and tend to not be the focus of much of the literature in comparison to those studies focusing on auditing sustainability in institutional operations. Additionally, the comparative audits of PSE sustainability with other fields are undertaken only in relation to corporations that use sustainability criteria to measure their performance, with little exploration in relation to other fields outside of business.

While the analysis of this literature has allowed for a perfunctory understanding of dominant themes within the comparative research on sustainability initiatives within PSE institutions, it is by no means an all-encompassing work. Because this review has drawn heavily on literature from educational research (six of the eight most cited journals discussing the topic were exclusively education journals, while the other two publish extensively on education), a meaningful step forward would be to take to heart many of the critiques of sustainability in post-secondary education within the literature and expand the review to draw on more interdisciplinary research for further understanding. Compelling research on sustainability within PSE institutions may very well be occurring outside of the academic literature on education, especially as sustainability itself is a growing field in and of itself, as evidenced by the increasing number of journals devoted to the topic [80]. The fact that so much of the research on sustainability in PSE curricula focuses on the disciplines of engineering and material sciences suggests that engineering journals may be a good place to start. Finally, as within any discipline, what is occurring within the field is not always observed nor written about by those within the ivory tower, even or especially when the topic is the ivory tower. Therefore, it is important to caution that a paucity of evidence in the literature may not necessarily be indicative of what is being practiced on the ground. Academic literature gives crucial insights into the field of sustainability in PSE institutions, but it is not the whole story. However, this work can serve as a foundation for future studies and we believe offers a "lay of the land" for those engaged in research on furthering sustainability through post-secondary education.

\section{Acknowledgments}

This paper draws on research supported by a Partnership Grant from the Social Sciences and Humanities Research Council of Canada (Grant No. 895-2011-1025, Primary Investigator Marcia McKenzie). A list of team members and organizational partners is included in [81].

\section{Conflict of Interest}

The authors declare no conflict of interest. 


\section{References and Notes}

1. Wright, T.; Pullen, S. Examining the literature: A bibliometric study of ESD journal articles in the education resources information center database. J. Educ. Sustain. Dev. 2007, 1, 77-90.

2. American Association of State Colleges and Universities. Top 10 State Policy Issues for Higher Education in 2009. Policy Matters: A Higher Education Policy Brief. 2009, 6. Available online: http://www.aascu.org/policy/publications/policymatters/2009/topten.pdf (accessed on 15 January 2013).

3. Feldbaum, M. Going Green: The Vital Role of Community Colleges in Building a Sustainable Future and Green Workforce; Academy for Educational Development: Washington, DC, USA, 2009.

4. OECD. On the Edge: Securing a Sustainable Future for Higher Education. In OECD Education Working Papers; OECD Publications: Paris, France, 2007. Available online: http://www.oecd.org/ edu/imhe/imheoecdforumonhighereducationpublications.htm/ (accessed on 5 December 2012).

5. The Association for the Advancement of Sustainability in Higher Education. STARS Technical Manual Version 1.2. Available online: http://www.aashe.org/files/documents/STARS/ stars_1.2_technical_manual.pdf (accessed on 24 January 2013).

6. Jacobson, B. The Illinois community college sustainability network-A successful model. Commun. College J. Res. Prac. 2010, 34, 929-931.

7. Corcoran, P.B.; Walker, K.E.; Wals, A.E.J. Case studies, make-your-case studies, and case stories: A critique of case-study methodology in sustainability in higher education. Environ. Educ. Res. 2004, 10, 7-21.

8. Swearingen White, S. Early participation in the American college and university presidents' climate commitment. Int. J. Sustain. Higher Educ. 2009, 10, 215-227.

9. Wright, T.S. Definitions and frameworks for environmental sustainability in higher education. Higher Educ. Policy 2002, 15, 105-120.

10. Vincent, S.; Focht, W. US higher education environmental program managers' perspectives on curriculum design and core competencies. Int. J. Sustain. Higher Educ. 2009, 10, 164-183.

11. Karatzoglou, B. An in-depth literature review of the evolving roles and contributions of universities to education for sustainable development. J. Clean. Prod. 2012, 49, 44-53.

12. Mochizuki, Y.; Fadeeva, Z. Regional centres of expertise on education for sustainable development (RCEs): An overview. Int. J. Sustain. Higher Educ. 2008, 9, 369-381.

13. Fink, A. Conducting Research Literature Reviews: From the Internet to Paper; Sage: Los Angeles, CA, USA, 2010.

14. Mayring, P. Qualitative content analysis. FQS_Forum: Qualitative Social Research 1 (2). Available online: http://www.utsc.utoronto.ca/ kmacd/IDSC10/Readings/text\%20analysis/CA.pdf (accessed on 21 December 2012).

15. Rusinko, C.A. Integrating sustainability in higher education: A generic matrix. Int. J. Sustain. Higher Educ. 2010, 11, 250-259.

16. Mulder, K.F.; Segalàs, J.; Ferrer-Balas, D. How to educate engineers for/in sustainable development. Int. J. Sustain. Higher Educ. 2012, 13, 211-218. 
17. Niu, D.; Jiang, D.; Li, F. Higher education for sustainable development in China. Int. J. Sustain. Higher Educ. 2010, 11, 153-162.

18. Stelmack, C.M.; Sinclair, A.J.; Fitzpatrick, P. An overview of the state of environmental assessment education at Canadian universities. Int. J. Sustain. Higher Educ. 2005, 6, 36-53.

19. Wright, H.A.; Ironside, J.E.; Gwynn-Jones, D. The current state of sustainability in bioscience laboratories. Int. J. Sustain. Higher Educ. 2008, 9, 282-294.

20. Sherren, K. Core issues. Int. J. Sustain. Higher Educ. 2006, 7, 400-413.

21. McKeown, R. Teacher education 1992 and 2012: Reflecting on 20 years. J. Educ. Sustain. Dev. 2012, 6, 37-41.

22. MacVaugh, J.; Norton, M. Introducing sustainability into business education contexts using active learning. Int. J. Sustain. Higher Educ. 2012, 13, 72-87.

23. Naeem, M.A.; Peach, N.W. Promotion of sustainability in postgraduate education in the Asia Pacific region. Int. J. Sustain. Higher Educ. 2011, 12, 280-290.

24. Holdsworth, S.; Wyborn, C.; Bekessy, S.; Thomas, I. Professional development for education for sustainability. Int. J. Sustain. Higher Educ. 2008, 9, 131-146.

25. Geli de Ciurana, A.M.; Filho, W.L. Education for sustainability in university studies: Experiences from a project involving European and Latin American universities. Int. J. Sustain. Higher Educ. 2006, 7, 81-93.

26. Corcoran, P.B.; Koshy, K.C. The pacific way: Sustainability in higher education in the South Pacific island nations. Int. J. Sustain. Higher Educ. 2010, 11, 130-140.

27. Lipscombe, B.P.; Burek, C.V.; Potter, J.A.; Ribchester, C.; Degg, M.R. An overview of extra-curricular education for sustainable development (ESD) interventions in UK universities. Int. J. Sustain. Higher Educ. 2008, 9, 222-234.

28. Davis, S.A.; Edmister, J.H.; Sullivan, K.; West, C.K. Educating sustainable societies for the twenty-first century. Int. J. Sustain. Higher Educ. 2003, 4, 169-179.

29. Savelyeva, T.; McKenna, J.R. Campus sustainability: Emerging curricula models in higher education. Int. J. Sustain. Higher Educ. 2011, 12, 55-66.

30. Wiek, A.; Withycombe, L.; Redman, C.L. Key competencies in sustainability: A reference framework for academic program development. Sustain. Sci. 2011, 6, 203-219.

31. Rieckmann, M. Future-oriented higher education: Which key competencies should be fostered through university teaching and learning? Futures 2012, 44, 127-135.

32. Ferrer-Balas, D.; Adachi, J.; Banas, S.; Davidson, C.I.; Hoshikoshi, A.; Mishra, A.; Motodoa, Y.; Onga, M.; Ostwald, M. An international comparative analysis of sustainability transformation across seven universities. Int. J. Sustain. Higher Educ. 2008, 9, 295-316.

33. James, M.; Card, K. Factors contributing to institutions achieving environmental sustainability. Int. J. Sustain. Higher Educ. 2012, 13, 166-176.

34. Shepard, J.; Johnson, L. Implementing sustainable institutional practices. J. Educ. Sustain. Dev. 2009, 3, 217-220.

35. Stephens, J.C.; Hernandez, M.E.; Román, M.; Graham, A.C.; Scholz, R.W. Higher education as a change agent for sustainability in different cultures and contexts. Int. J. Sustain. Higher Educ. 2008, 9, 317-338. 
36. Velazquez, L.; Munguia, N.; Sanchez, M. Deterring sustainability in higher education institutions: An appraisal of the factors which influence sustainability in higher education institutions. Int. J. Sustain. Higher Educ. 2005, 6, 383-391.

37. Pearce, J.M. Catalyzing mass production of solar photovoltaic cells using university driven green purchasing. Int. J. Sustain. Higher Educ. 2006, 7, 425-436.

38. Dale, A.; Newman, L.; Ling, C. Facilitating transdisciplinary sustainable development research teams through online collaboration. Int. J. Sustain. Higher Educ. 2010, 11, 36-48.

39. Ryan, A.; Tilbury, D.; Corcoran, P.B.; Abe, O.; Nomura, K. Sustainability in higher education in the Asia-Pacific: Developments, challenges, and prospects. Int. J. Sustain. Higher Educ. 2010, 11, $106-119$.

40. Nomura, K.; Abe, O. Higher education for sustainable development in Japan: Policy and progress. Int. J. Sustain. Higher Educ. 2010, 11, 120-129.

41. Galang, A.P. Environmental education for sustainability in higher education institutions in the philippines. Int. J. Sustain. Higher Educ. 2010, 11, 173-183.

42. Banga Chhokar, K. Higher education and curriculum innovation for sustainable development in India. Int. J. Sustain. Higher Educ. 2010, 11, 141-152.

43. Arvidsson, K. Environmental management at Swedish universities. Int. J. Sustain. Higher Educ. 2004, 5, 91-99.

44. Sammalisto, K.; Arvidsson, K. Environmental management in Swedish higher education: Directives, driving forces, hindrances, environmental aspects and environmental co-ordinators in Swedish universities. Int. J. Sustain. Higher Educ. 2005, 6, 18-35.

45. Blewitt, J. Education for sustainable development, governmentality and "learning to last". Environ. Educ. Res. 2005, 11, 173-185.

46. Beringer, A. The Lüneburg sustainable university project in international comparison. Int. J. Sustain. Higher Educ. 2007, 8, 446-461.

47. Beringer, A.; Wright, T.; Malone, L. Sustainability in higher education in Atlantic Canada. Int. J. Sustain. Higher Educ. 2008, 9, 48-67.

48. Sowell, A.; Eichel, A.; Alevantis, L.; Lovegreen, M. Building better buildings: Sustainable building activities in california higher education systems. Plan. Higher Educ. 2003, 31, 120-130.

49. Martin, R.J. STARS: A campus-wide integrated continuous planning opportunity. Plan. Higher Educ. 2011, 39, 41-47.

50. Way, T.; Matthews, C.; Rottle, N.; Toland, T.R. Greening the American campus: Lessons from campus projects. Plan. Higher Educ. 2012, 40, 25-47.

51. Alfieri, T.; Damon, D.; Smith, Z. From living buildings to living campuses. Plan. Higher Educ. 2009, 38, 41-50.

52. Brown, J.P.; Hillman, L.R. Truly green: A look at the advantages of maintaining historic campus buildings. Facil. Manag. 2010, 26, 26-30.

53. Williamson, S.R. A systems approach to reducing institutional GHG emissions. Int. J. Sustain. Higher Educ. 2012, 13, 46-59.

54. Comm, C.L.; Mathaisel, D.F.X. Sustaining higher education using wal-mart's best supply chain management practices. Int. J. Sustain. Higher Educ. 2008, 9, 183-189. 
55. Arikewuyo, O.M. Restructuring as a panacea for the sustainable development of the Nigerian University system. Higher Educ. Policy 2009, 22, 245-257.

56. Clugston, R.; Calder, W. Food and higher education for sustainable development. J. Educ. Sustain. Dev. 2007, 1, 209-218.

57. Chen, C.J.; Gregoire, M.B.; Arendt, S.; Shelley, M.C. College and university dining services administrators' intention to adopt sustainable practices. Int. J. Sustain. Higher Educ. 2011, 12, $145-162$.

58. Finlay, J.; Massey, J. Eco-campus: Applying the ecocity model to develop green university and college campuses. Int. J. Sustain. Higher Educ. 2012, 13, 150-165.

59. Richard, R. Ecocities: Building Cities in Balance with Nature; Berkeley Hills Books: Berkeley, CA, USA, 2002; p. 290.

60. Su, H.J.; Chang, T. Sustainability of higher education institutions in Taiwan. Int. J. Sustain. Higher Educ. 2010, 11, 163-172.

61. Martin, F.E. The puzzles and promise of campus landscape preservation: Integrating sustainability, historic landscapes, and institutional change. Plan. Higher Educ. 2011, 39, 167-178.

62. Beringer, A. Campus sustainability audit research in Atlantic Canada: Pioneering the campus sustainability assessment framework. Int. J. Sustain. Higher Educ. 2006, 7, 437-455.

63. Glover, A.; Peters, C.; Haslett, S.K. Education for sustainable development and global citizenship: An evaluation of the validity of the STAUNCH auditing tool. Int. J. Sustain. Higher Educ. 2011, $12,125-144$.

64. Roorda, N.; Martens, P. Assessment and certification of higher education for sustainable development. Sustainability 2008, 1, 41-56.

65. Madeira, A.C.; Carravilla, M.A.; Oliveira, J.F.; Costa, C.A. A methodology for sustainability evaluation and reporting in higher education institutions. Higher Educ. Policy 2011, 24, 459-479.

66. Di Giulio, A.; Ruesch Schweizer, C.; Adomßent, M.; Blaser, M.; Bormann, I.; Burandt, S.; Fischbach, R.; Kaufmann-Hayoz, R.; Krikser, T.; Künzil David, C.; et al. Education on the path to sustainability: Proposal of an indicator set to evaluate education for sustainable development. 2012. Available online: http://www.ikaoe.unibe.ch/publikationen/zusammenfassungen/reihe.a.13.html (accessed on 4 March 2013).

67. Tilbury, D. Tracking our progress: A global monitoring and evaluation framework for the UN DESD. J. Educ. Sustain. Dev. 2009, 3, 189-194.

68. Yarime, M.; Tanaka, Y. The issues and methodologies in sustainability assessment tools for higher education institutions: A review of recent trends and future challenges. J. Educ. Sustain. Dev. 2012, 6, 63-77.

69. Mader, C. How to assess transformative performance towards sustainable development in higher education institutions. J. Educ. Sustain. Dev. 2012, 6, 79-89.

70. Adomssent, M.; Michelsen, G. German academia heading for sustainability? Reflections on policy and practice in teaching, research and institutional innovations. Environ. Educ. Res. 2006, 12, 85-99.

71. Lozano, R. The state of sustainability reporting in universities. Int. J. Sustain. Higher Educ. 2011, $12,67-78$. 
72. Walton, S.V.; Galea, C.E. Some considerations for applying business sustainability practices to campus environmental challenges. Int. J. Sustain. Higher Educ. 2005, 6, 147-160.

73. Fisher, R.M. Applying ISO 14001 as a business tool for campus sustainability: A case study from New Zealand. Int. J. Sustain. Higher Educ. 2003, 4, 138-150.

74. Price, T.J. Preaching what we practice: Experiences from implementing ISO 14001 at the university of Glamorgan. Int. J. Sustain. Higher Educ. 2005, 6, 161-178.

75. Universities that Count: A Report on Benchmarking Environmental and Corporate Responsibility in Higher Education; EAUC Report: Leeds, UK, 2007. Available online: http://www.eauc.org.uk/ universities_that_count_-_he_benchmarking_report/ (accessed on 7 January 2013).

76. People and Planet Green League Guide 2013; People and Planet Report: Oxford, UK, 2013. Available online: http://peopleandplanet.org/dl/greenleague/2013/guide.pdf (accessed on 29 January 2013).

77. Rauch, J.N.; Newman, J. Defining sustainability metric targets in an institutional setting. Int. J. Sustain. Higher Educ. 2009, 10, 107-117.

78. Fonseca, A.; Macdonald, A.; Dandy, E.; Valenti, P. The state of sustainability reporting at Canadian universities. Int. J. Sustain. Higher Educ. 2011, 12, 22-40.

79. Bornman, G.M. Programme review guidelines for quality assurance in higher education: A South African perspective. Int. J. Sustain. Higher Educ. 2004, 5, 372-383.

80. Rowe, D. Education for a sustainable future. Science 2007, 317, 323-324.

81. The Sustainability and Education Policy Network. Available online: https://www.sepn.ca/ (accessed on 30 January 2013).

(C) 2013 by the authors; licensee MDPI, Basel, Switzerland. This article is an open access article distributed under the terms and conditions of the Creative Commons Attribution license (http://creativecommons.org/licenses/by/3.0/). 